\title{
Research on the Construction of the Lighting Project of Taoping Qiang Village under the Contemporary Digital Landscape Design
}

\author{
Baiyu Chen \\ Southwest Minzu University, Chengdu, China \\ Email: 1016696049@qq.com
}

How to cite this paper: Chen, B. Y. (2020). Research on the Construction of the Lighting Project of Taoping Qiang Village under the Contemporary Digital Landscape Design. Open Journal of Social Sciences, 8, 274-283.

https://doi.org/10.4236/jss.2020.84020

Received: March 25, 2020

Accepted: April 17, 2020

Published: April 20, 2020

Copyright $\odot 2020$ by author(s) and Scientific Research Publishing Inc. This work is licensed under the Creative Commons Attribution International License (CC BY 4.0).

http://creativecommons.org/licenses/by/4.0/

\begin{abstract}
This paper introduces the relevant concepts of lighting engineering and its digital development trend. By combining the current state of Taoping Qiang Village, on the basis of analyzing and summarizing its cultural connotation, this paper discusses the construction method of lighting engineering that is suitable for Taoping Qiang village. According to the research, the lighting design of Taoping Qiang Village should take protection as the principle and guided design as the method to enhance the dynamic creation of the root cultural connotation, so as to better inherit and innovate the Qiang culture.
\end{abstract}

\section{Keywords}

Lighting Engineering, Taoping Qiang Village, Cultural Inheritance, Regional Culture

\section{Introduction}

The inheritance and protection of Qiang culture are the focus of the development of Qiang area. As a representative of the Qiang culture with a history of thousands of years, the construction of the lighting engineering can make the cultural inheritance of Taoping Qiang Village more visual and diversified, and bring economic benefits. But as people's demands for spiritual culture generally promote, lighting engineering has become a double-edged sword: Ordinary and featureless lighting not only spends money, still can let the night scenery of the Qiang areas become common due to the loss of recognition. While it can improve a certain amount of economic benefit, but it will have a discount on the protection and inheritance of cultural aspects. 


\section{Integration of Digital Landscape and Lighting Engineering}

1) Concept of lighting engineering

Lighting engineering (also known as the urban night landscape) refers to the lighting of landmark buildings, tourist attractions, streets and other places with large flow in order to beautify the urban environment and improve the overall image of the city. Through the lighting engineering, the relationship between the subject and the object formed by buildings, scenic spots and the crowd can be realized, and the direct and effective dialogue and communication can be carried out. It can cause the psychological and emotional reaction of the main crowd at the first time: Satisfaction, pleasure, exclamation, vision, etc. and form the first impression, which is often the most distinct and firm.

2) Basic types of lighting engineering construction

a) Light of the existing carrier. That is to say, the night landscape construction of the main landscape is also the most common way of lighting. Lighting is presented on the existing bearing body to complete the transition of the object landscape from day landscape to night landscape and enhance the visibility. For example, the exterior facade of the building at night can enhance the architectural beauty and present different visual scenes through different forms such as architectural contour lighting and wall washing lighting.

b) Lighting of specific theme space. That is to say, the lighting construction of the space scene which needs to express the deep cultural connotation and theme. For example, the water lighting show, square lighting show, etc. an attractive and colorful visual scene is created by the means of the specific lighting, forming the most hot area in the whole landscape.

c) Lighting the sketch. In addition to its function, the lighting equipment also has certain artistry, which is the integration of the landscape sketch and lighting (Cai, 2015). Most of them are used in landscape scenes with insufficient congenital conditions and lack of light sources. For example, the customized plastic lamps, lighting statues, lighting installation art, etc., can express certain cultural connotation and background atmosphere in the scene.

In the construction of the lighting engineering, the construction type should be chosen in accordance with the specific requirements and circumstances of the scene, and the proportion of different types should be coordinated to create a clear theme and harmonious scene space.

3) Current situation and prospect of lighting engineering in scenic spot

The transitional construction lacks regional characteristics. Taking the cultural building scenic spot as an example, the lighting engineering brings rapid economic benefits and image enhancement, which makes different cities and scenic spots accelerate the construction of lighting, which results in the uniform lighting of buildings in ancient building scenic spots all over the country, with bright lights at night (Figure 1). There are a large number of copies and pastes on the contents, which leads to the homogenization of most of today's cultural architecture scenic spots. "Familiar" is the general impression of tourists on the scenic 




Figure 1. Mao Xian—“The ancient city of China”-Lighting Project.

spots. The lighting design should be different from city to place, which is unique and memorable, and it is just the real need of the people who need more and more spiritual culture today.

4) Integration of digital landscape design and lighting engineering

At present, the lighting engineering is lack of individuality and recognition. Generally, it is simple lighting and flickering, focusing on the creation of the beauty of the object itself as a whole. Although it has better practicability and economy, it lacks the interactive relationship and cultural expression with people, which is easy to cause the aesthetic fatigue of the main crowd for a long time.

In the context of the information age, the digital landscape design can create a new carrier landscape beyond the traditional form of landscape expression and imagination, forming a multi controllable landscape space. People will pay more attention to the connection, information acquisition and user experience in the environmental space. The multi-dimensional and controllable landscape space is the challenge faced by the lighting engineering today. The development of the lighting engineering should meet the information interaction between human, lighting and environment. Through digital technology, the night landscape activation will move towards "Warm people" and narrating stories.

\section{Key Points in the Construction of Lighting Project in Taoping Qiang Village}

1) There is a certain gap between the new village and the old village

After the earthquake, Taoping Qiang village seized the historical opportunity of post disaster reconstruction and built the first 4A scenic spot with Qiang culture as the theme with the goal of "Old fort and new village". A new Qiang village has been built beside the old village, which has serious traces of artificial 
later stage. At night, the new village lights up a variety of lights, and the old village disappears into the night, which makes its original culture difficult to express, and also makes the old village and the new village lack of connection (Figure 2).

2) Advantage treatment of wind

The wind energy resources in Qiang area is one of the largest in Sichuan Province, and the application of wind will directly affect the overall effect of lighting project: If ignored, its huge wind will hinder the night viewing experience of tourists and weaken the effect of landscape space; Only by integrating the attributes of wind into the design, can we better respond to the environment and transform the negative impact of strong wind into a powerful driving force for optimizing lighting engineering.

3) The protective design of the old village

The main function of the old village is "Cultural relics protection unit" rather than landscape architecture, so we can't put the cart before the horse. Its unique cultural connotation and history require us to go close to the building and observe the details of doors and windows, stone carvings, etc. inside and outside, rather than lighting (Figure 3). If only the building is lit up, it is a reflection of the lack of the recognition of the core value of cultural relic buildings. The lighting design should respect the historical original appearance of the building and integrate into the environment in a more gentle way. Therefore, to grasp the core culture of Taoping Qiang Village and express it is the key point of lighting engineering construction.

\section{Cultural Connotation and Value of Qiang Traditional Villages}

Taoping Qiang Village is the most famous building with the reputation of "Mysterious oriental ancient castle". In 2008, it is listed in the preparatory list of world cultural heritage application, which is the epitome of Qiang's millennium history.

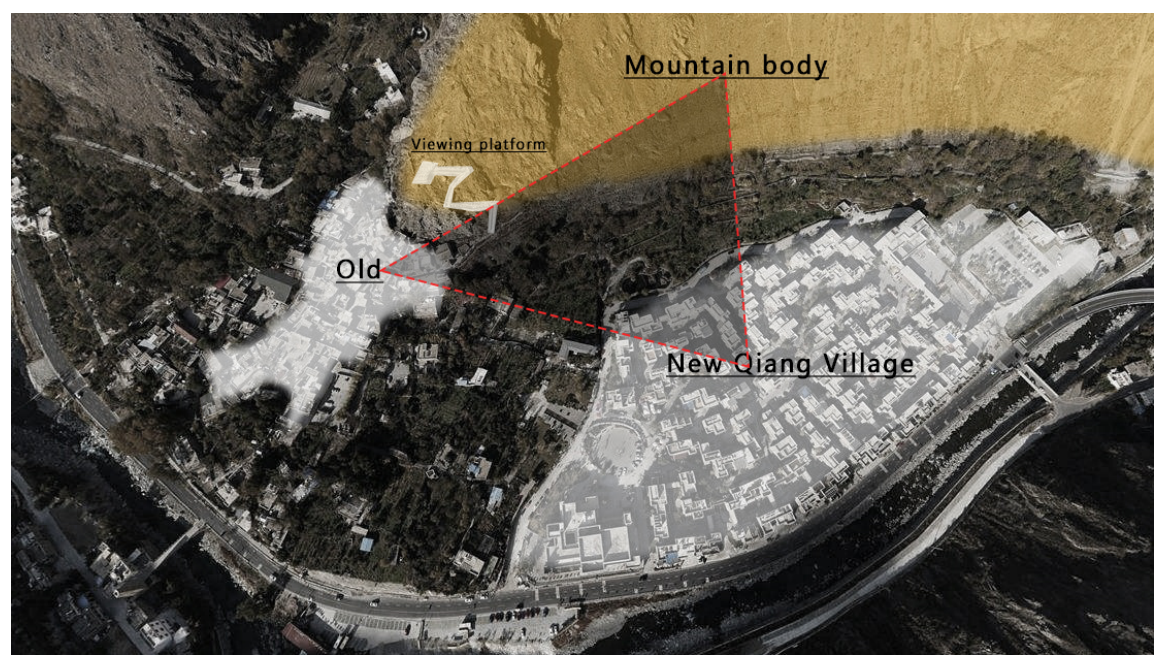

Figure 2. New village and the old village. 

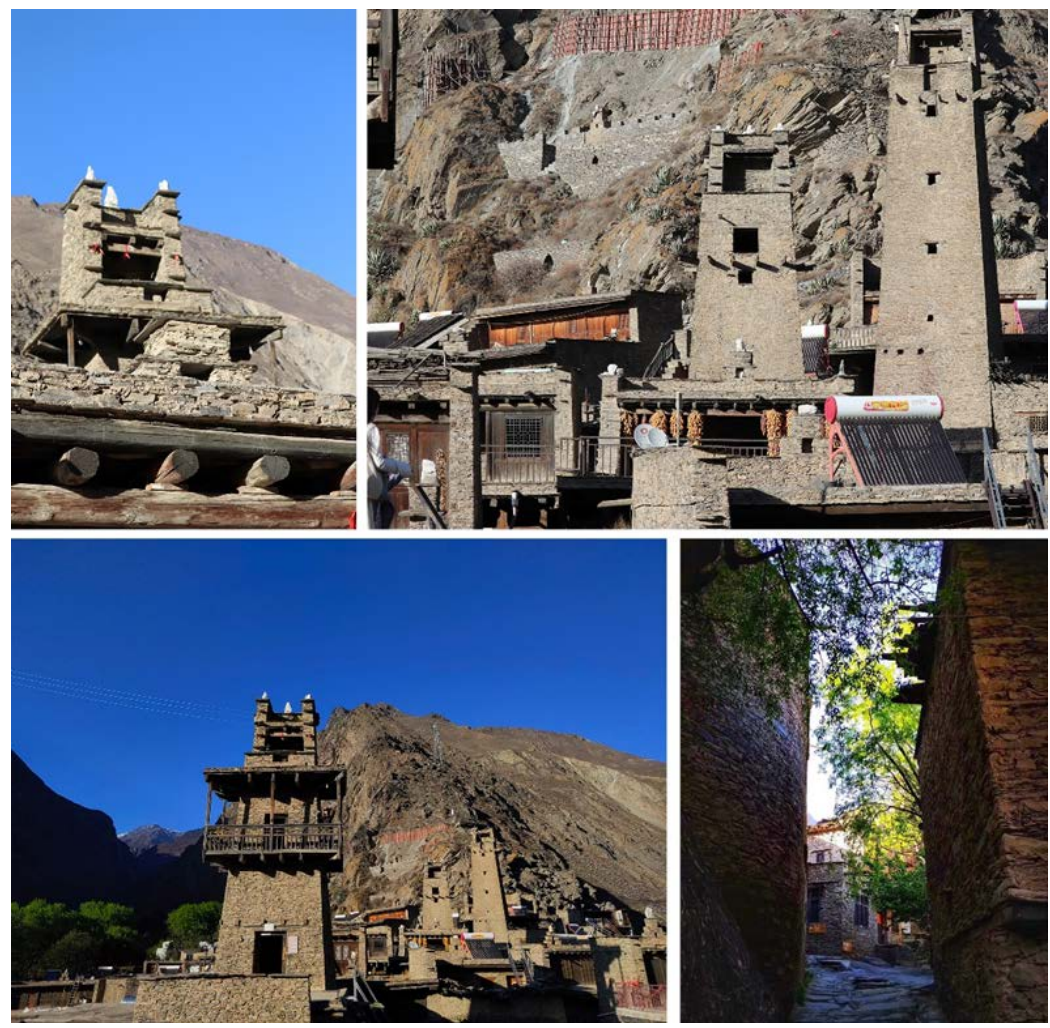

Figure 3. Old village building.

1) Architectural culture under the background of keeping the root and strengthening the foundation

Qiang is a nation that has experienced many migrations. Through the baptism of the years, it has formed a very strong cohesive force and is perfectly reflected in the architecture: An ancient building built entirely of yellow mud and rubble. In the past hundred years, it has withstood three earthquakes of magnitude 7.0 or above, and the whole structure is still intact.

a) The architecture of Qiang village is the spiritual symbol of the unity and cooperation of Qiang people. There will be a certain hole in the building wall of Qiang village, which is for the convenience of the future residents to build each other in accordance with their needs. This kind of building is called the crossing building (Figure 4). The crossing building makes the whole village become a dense large building, and forms the indoor transportation system. At the same time, it is precisely because of the unique building form of the arcade that the seismic performance of the whole building is strengthened (Ji, 2000).

b) The unique building presents the traffic network with light and shadow changes (Figure 5). Most of the roadways are tightly wrapped by buildings, half of which are open to the sky and half of which are covered in the interior of the buildings, demonstrating the ultimate light and shadow changes. The people in the village know their unique road layout very well, while the people outside the village face such a road network, like entering the maze of light and shadow alternation. Without the guidance of local residents, it is difficult to pass. 


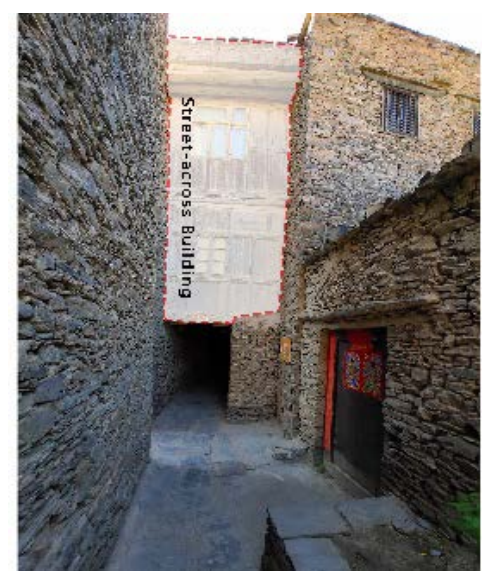

Figure 4. Crossing building.

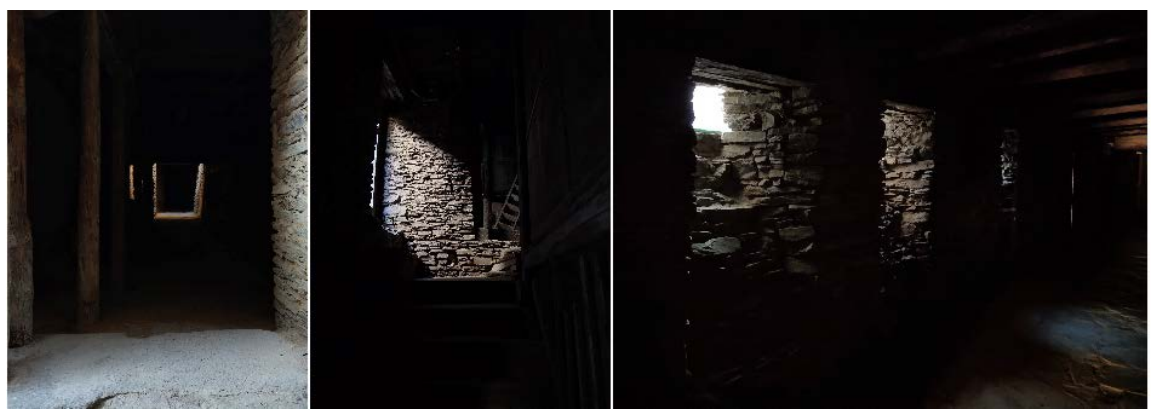

Figure 5. Traffic network with light and shadow changes.

c) The architecture of Qiang village shows the wisdom of Qiang people. This kind of village, which appears to be a little crowded from the ground, does not block the smooth connection between the Qiang people at all. Qiang people regard the roof as a social platform. The roofs of neighboring families are scattered and connected with each other, forming a complete air traffic system, with a panoramic view of the natural scenery. This is a sharp contrast with the complex and narrow ground roadway.

It is this kind of architectural art and the cultural connotation it contains that has become the fortress of Qiang people's spirit and culture, constructing the national character of unity in close space, and it demonstrated the heroic spirit of Qiang people's wisdom. It has become the most prominent feature and tourist card of Qiang culture.

2) Pure human landscape

Qiang embroidery is a unique skill of Qiang women and an important cultural heritage of Qiang people. Because Qiang is a nation without words, Qiang embroidery has become a carrier of national culture. Between the stitches of Qiang embroidery, the rich cultural connotation of Qiang nationality is conveyed vividly and implicitly.

In addition, there are many cultural landscapes of the Qiang nationality, such as the mysterious "Taishan Shigandang" (Figure 6), "White stone worship" (Figure 7), "Sheep totem worship" (Figure 8), "Playing Qiang Flute”, etc., which 


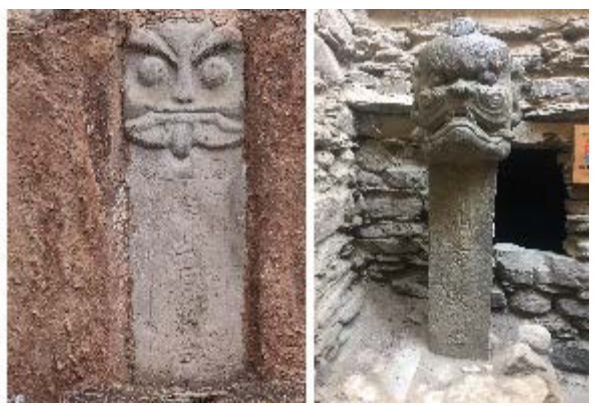

Figure 6. "Taishan Shigandang".


Figure 7. "White stone worship".

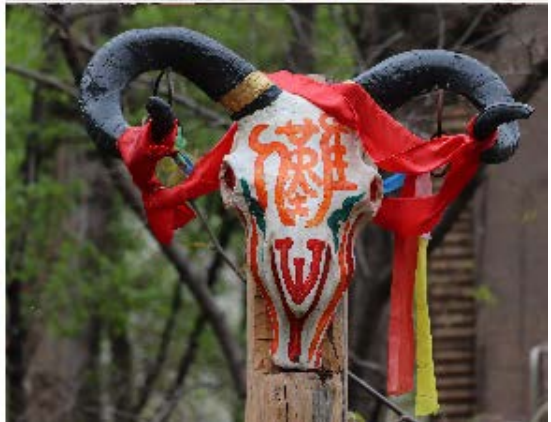

Figure 8. "Sheep totem worship".

are integrated into the architecture of each Qiang people in the root system and bloom in the world. In the face of this unique historical culture and art precipitation, it is particularly important to protect and inherit the culture in the design.

\section{Discussion on the Activation and Innovative Development of Qiang Culture under the Light Project}

1) The lateral fusion of old village and new village

In the face of the gap between the old and the new Qiang villages in the night landscape, the principle is to respect and protect the historical original appearance of cultural buildings, and the mountains behind the Qiang villages are selected as the lighting carrier to form the theme space. With the help of today's 
digital technology, mountain projection lamp can realize the combination of lighting technology and video technology. In terms of the content, Qiang embroidery is used as the expression element, forming a needle and thread weaving pattern with mountains as the starting point, outlining the Qiang culture, so as to connect the new village and the old village, activate the Qiang culture, and express the inheritance of the old village and the development of the new village.

2) A variety of inductive lighting products

a) Because of its unique geographical location, the wind has become an obvious element for every tourist experience. In the lighting design, the Qiang cultural symbols such as white stone and the sheep totem are extracted to form the lighting sketch, and the wind induction control components are given. When the wind is strong, the light is fast and the rhythm is strong; when the wind is small, the light is gentle and the change is slow. According to the terrain height, the group design is carried out. The more layers are, the richer the lighting changes will be, making Taoping Qiang Village more dynamic and rhythmic (Figure 9). At the same time, it also gives the dynamic expression of Qiang cultural symbols and strengthens the cognition of the people to the symbols so as to further explore.

b) During the day, due to the compactness of its buildings, Taoping Qiang Village also has an amazing relationship between light and shadow, which enables the Qiang village in the day to add bright landscape elements. Let the light interact with the tourists. When the tourists pass by, brighten the small pieces to change the light, shade and color. The small pieces are endowed with local folk elements such as shigandang in the shape, so that the labyrinth of the village can further add a sense of solemnity and mystery, and enhance the tourists' desire for exploration.

3) Local lighting of buildings

Light with shadow, less is more, and simple is complex. At night, the projection of light can generalize the visual representation of complex building structure. From the normal perspective, the main building is concealed in the dark

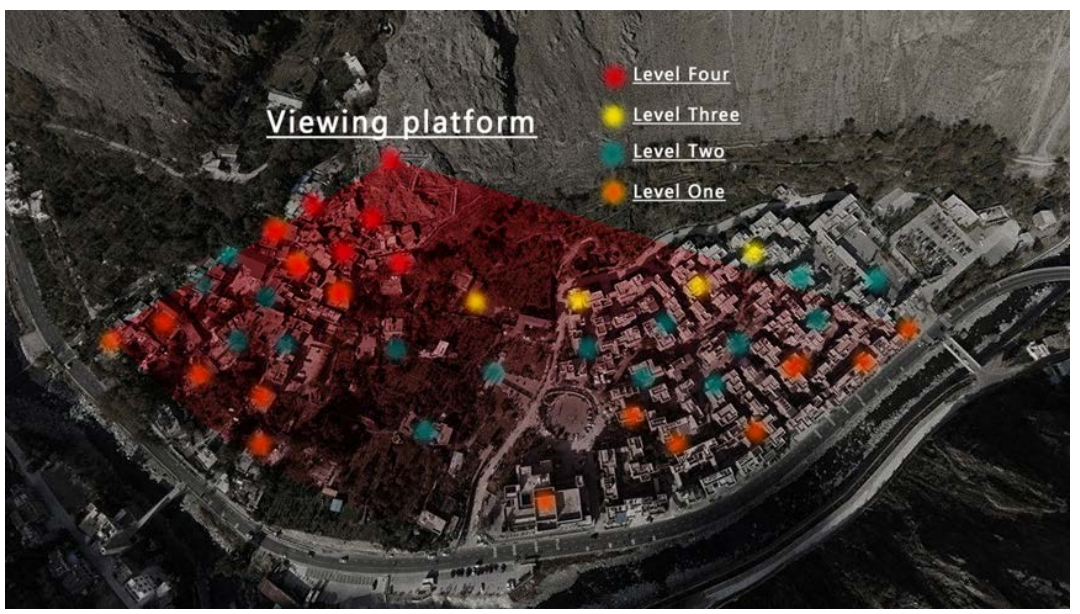

Figure 9. Group design of Lighting the sketch. 

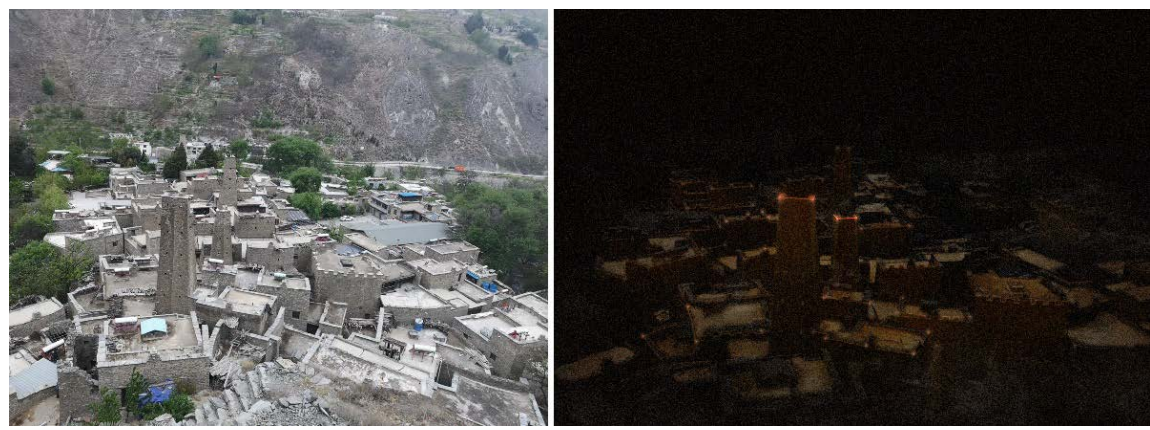

Figure 10. Local lighting of buildings.

through the weak lighting of some parts of Taoping Qiang Village, such as the air platform, crossing building, blockhouse, groundwater network, etc. (Figure 10). This kind of local lighting makes the building strange, so that visitors can get new understanding from the strange (Song, 2013), and let the architectural culture of Qiang village spread more actively.

\section{Conclusion}

The construction of lighting engineering of Taoping Qiang Village and its cultural architecture landscape is deeply rooted in regional culture. What should be done in the construction of its lighting project is to play a guiding role in cultural communication, how to enhance cultural value and cultural understanding through lighting, so as to better cultural heritage of scenic spots. Instead of reversing the primary and secondary, let the bright and beautiful transition cover the culture. At the same time, in the construction of lighting engineering, we should strengthen the root cultural connotation construction, combine the contemporary digital technology into the lighting to carry out the dynamic expression among people, light and environment, and create a more personalized, fresh and beautiful landscape space, so as to make the culture activated and more vivid and closer expression, which is conducive to enhancing the attraction of Qiang village.

Secondly, taking Taoping Qiang Village lighting engineering as the point, it will be applied to the whole Qiang area to create a cultural image of "Breathing together", and its cultural heritage will be changed from individual expression to the maximum effect of group expression. This will change the current situation of homogenization and lack of features of most cultural scenic spots to some extent, so as to make the lighting engineering of cultural scenic spots to have "Temperature" and "Vitality" will be more conducive to the inheritance and development of culture, so as to better reflect the national spirit and group memory.

\section{Acknowledgements}

This project is funded by the graduate innovative scientific research project [grant number: CX2019SZ188] of Southwest University for Nationalities. 


\section{Conflicts of Interest}

The author declares no conflicts of interest regarding the publication of this paper.

\section{References}

Cai, X. (2015). Application of LED Light Source in Urban Landscape Lighting Design. Architecture Building Materials Decoration, No. 15, 25.

Ji, F. Z. (2000). Chinese Qiang Architecture. Chengdu: Southwest Jiaotong University Press.

Song, J. H. (2013). Rational Interpretation of Night Landscape Design: Preliminary Discussion on Urban Lighting Engineering. Chinese and Foreign Architecture, No. 7, 71-74. 